\title{
Overexpression of humbug promotes malignant progression in human gastric cancer cells
}

\author{
JEONG-HYUNG LEE
}

\author{
Department of Biochemistry and Research Institute of Life Science, College of \\ Natural Sciences, Kangwon National University, Chuncheon 200-701, Korea
}

Received August 9, 2007; Accepted October 19, 2007

\begin{abstract}
Two human gastric cancer cell lines of differing invasive potential, SNU-484 and SNU-638 cells, were examined using subtractive suppression hybridization in a search for any genes associated with metastasis. Of the eight cDNAs identified as being differentially expressed genes, it was determined that humbug, which encodes a truncated isoform of aspartyl (asparaginyl) ß-hydroxylase (AAH) missing catalytic domain, was overexpressed in highly invasive SNU-638 cells. Expression analysis showed that the mRNA expression level of humbug was correlated with invasive potential in various human gastric cancer cell lines. The forced expression of humbug to the human gastric cancer cell line AGS increased its anchorage-independent growth in $0.3 \%$ agar without affecting cell proliferation. Furthermore, humbug-transfected cells migrated more actively and showed an increased invasion rate relative to vector-transfectants or parental AGS in vitro. This is the first demonstration that humbug, a truncated form of AAH, can be overexpressed during the malignant progression of human gastric cancer cells and that it can function as a metastasis-inducing gene.
\end{abstract}

\section{Introduction}

On a worldwide basis, gastric cancer is one of the most common causes of cancer mortality (1). The treatment of this disease, however, has improved due to early detection followed by surgical resection, emphasizing the need to develop efficient biomarkers to detect gastric cancer as early as possible (2). However, patients with advanced gastric cancer display poor prognosis even if they undergo curative resection, because systemic micrometastasis may have already existed at the time of surgery (3). Mechanisms involved in gastric cancer metastasis are not fully clarified since metastatic progression of

Correspondence to: Dr Jeong-Hyung Lee, Department of Biochemistry, College of Natural Sciences, Kangwon National University, Chuncheon 200-701, Korea

E-mail: jhlee36@kangwon.ac.kr

Key words: humbug, migration, invasion, anchorage-independent growth, gastric cancer the cancer cells requires the accumulation of altered expression of many different genes and involves multiple steps (4). Although aspects of metastatic progression of gastric cancer remain to be elucidated, several genes have been reported to regulate a positive or negative metastasis of gastric cancer cells (5-7). In the present study, we measured the invasive potential of various gastric cancer cell lines and subsequently performed suppression subtractive hybridization (SSH) to identify metastasis-related genes by comparing differential gene expression profiles between highly invasive SNU-638 and poorly invasive SNU-484 gastric cancer cell lines. Eight different genes were identified as being overexpressed in SNU-638 cells. Of these, we identified humbug, an alternative splicing variant of aspartyl (asparaginyl) Bhydroxylase (AAH), as an overexpressed gene in human gastric cancer cells.

In humans, the alternative splicing of aspartyl (asparaginyl) $ß$-hydroxylase (AAH) gene generates at least four transcripts which encode four distinct proteins $(8,9)$; an enzyme aspartyl (asparaginyl) B-hydroxylase, an isoform of aspartyl Bhydroxylase missing the catalytic domain (humbug), junctin, and junctate, which are generated by alternative splicing of an $\sim 6 \mathrm{~kb}$ mRNA transcript, with exon sharing and exon swapping mainly within the first 13 exons $(8,9)$. Humbug mRNA is derived from the first 14 exons of the AAH gene (8-11). Humbug can bind calcium and the overexpression of humbug increases intracellular calcium levels by promoting its release from intracellular stores and shares a high degree of sequence homology with junctate $(8,10)$.

Herein, we describe the overexpression of humbug in highly invasive human gastric cancer cell lines and its effect in enhancing the migration, invasion and anchorageindependent growth of a human gastric cancer cell line AGS in vitro. Our results suggest that humbug can be overexpressed in human gastric cancer cells and can promote the malignant progression and possibly metastasis of the cells.

\section{Materials and methods}

Cell lines. The gastric cancer cell lines SNU-1, -5, -16, -216, $-484,-620,-638$ and AGS were obtained from the Korean Cell Line Bank of the Cancer Research Center, Seoul National University College of Medicine and maintained in RPMI1640. The characteristics of these cell lines were described previously $(12,13)$. All media were supplemented with $10 \%$ fetal bovine serum, penicillin and streptomycin and all cell 
lines were maintained in a humidified $5 \% \mathrm{CO}_{2}$ atmosphere at $37^{\circ} \mathrm{C}$.

Suppression subtractive hybridization (SSH) and differential screening. SSH was performed between SNU-638 and SNU-484 using the PCR-Select ${ }^{\mathrm{TM}}$ cDNA subtraction kit (Clontech, Mountain View, CA, USA). SSH and differential screening were performed as described previously (14).

Northern blotting. Northern blotting was performed as previously described (14). To detect mRNA expression of the subtracted genes, inserts were excised from the pCR2.1 vector by EcoR I digestion and used for probes. To detect $A A H$ and humbug, a 714 bp Sma I-Xba I fragment in an open reading frame of humbug was used as a probe. Following hybridization, the membrane was washed and exposed to film with an intensifying screen at $-80^{\circ} \mathrm{C}$.

Construction of humbug expression vectors and transfection. To obtain the humbug cDNA, polymerase chain reaction (PCR) was performed with SNU-638 cDNA as a template and Advantage Polymerase Mix (Clontech). Specific primers for humbug were designed based on the previous sequence (Genbank accession number NM_032466); sense 5'-GCAAT GGCCCAGCGTAAGAAT-'3 and antisense 5'-GAAGCTTT AAGTATCTGGTGG-'3. After an initial denaturation step at $95^{\circ} \mathrm{C}$ for $2 \mathrm{~min}$, humbug was amplified for 30 cycles of $30 \mathrm{sec}$ at $94^{\circ} \mathrm{C} ; 1 \mathrm{~min}$ at $58^{\circ} \mathrm{C} ; 3 \mathrm{~min}$ at $72^{\circ} \mathrm{C}$. Amino-terminally FLAG-tagged humbug expression vectors were generated by cloning humbug cDNA into pCMV-Tag 2 (Stratagene, La Jolla, CA, USA) vector in frame. All sequences were verified by DNA sequencing. AGS cells were transfected with the pCMV Tag 2-FLAG-humbug using the Lipofectamine Plus (Invitrogen). Forty-eight hours after transfection, the medium was changed with the culture medium supplemented with $500 \mu \mathrm{g} / \mathrm{ml}$ of $\mathrm{G} 418$ for selection of stable transfectants.

Western blotting. Western blotting was performed as previously described (14). In brief, cells were washed with ice-cold PBS three times and extracted in ice-cold lysis buffer (50 mM Tris-HCl, pH 7.5, 1\% Nonidet P-40, $1 \mathrm{mM}$ EDTA, $1 \mu \mathrm{M}$ phenylmethyl sulfonyl fluoride, $1 \mathrm{mg} / \mathrm{ml}$ leupeptin, $150 \mathrm{mM} \mathrm{NaCl}$ ). Proteins were separated onto SDS-PAGE and transferred a Hybond-P membrane (Amersham Biosciences, Buckinghamshire, UK). The membranes were blocked and then incubated for $2 \mathrm{~h}$ with anti-FLAG M2 monoclonal antibody (Sigma, St. Louis, MO, USA). After washing, the membrane was incubated with the secondary antibody conjugated with horseradish peroxidase. The signal was detected using the Amersham ECL system (Amersham Pharmacia Biotech, Buckinghamshire, UK). To show the equal loading of protein, the membrane was stripped and reprobed with anti-tubulin antibody (InnoGenex, San Ramon, CA, USA).

Cell migration and invasion assay. A migration and invasion assay was performed as previously described $(14,15)$. In brief, the ability of cells to migrate through non-coated (migration) or invade through $10 \mu \mathrm{g}$ Matrigel-coated filters (invasion) was measured with a modified Boyden chamber (Corning Costar,
Cambridge, MA, USA); $8 \mu \mathrm{m}$ pore size. Cells were seeded at a density of $1 \times 10^{4}$ cells/100 $\mu \mathrm{l} /$ well. After incubation for $12 \mathrm{~h}$ (migration) or $24 \mathrm{~h}$ (invasion) at $37^{\circ} \mathrm{C}$ in $5 \% \mathrm{CO}_{2}$, the cells that had not penetrated the filter were completely wiped out with cotton swabs and the cells that had migrated to the lower surface of the filter were fixed, stained and counted in 5 randomly selected microscopic fields (x100) per filter. Three independent experiments were performed in triplicate and the data were represented as the average of the three independent experiments with the standard error of the average indicated. Statistical comparison was made using one-way ANOVA. P-values $<0.01$ were considered very significant.

Anchorage-independent growth in $0.3 \%$ agar. Six-well culture plates were covered with a layer of $0.5 \%$ agar in a medium supplemented with $20 \%$ FBS to prevent the attachment of the cells to the plastic substratum. Cell suspensions $(5,000$ cells/ well) of the control and humbug-transfected cells were prepared in $0.3 \%$ agar and poured into 6-well plates. The plates were incubated at $37^{\circ} \mathrm{C}$ in a humid atmosphere of $5 \%$ $\mathrm{CO}_{2}$ for 3 weeks until colonies appeared. The colonies were stained with crystal violet and counted. Colony assays were performed in triplicate three times and results are reported as a mean of three experiments.

Proliferation assay. The cells grown in RPMI-1640 supplemented with $10 \%$ FBS were placed in a 24 -well plate at a concentration of $1 \times 10^{4} / \mathrm{ml}$ cells per well. Following incubation for the indicated time, the viable cells were counted with a hemacytometer after trypan blue staining. Results were calculated as the mean $\pm \mathrm{SD}$ of triplicate cultures.

\section{Results}

In an effort to understand the invasive and metastatic progression of gastric cancer, we have used SSH to generate a profile of genes overexpressed in the highly invasive gastric cancer cell line. SSH was performed between SNU-638 (highly invasive phenotype) and SNU-484 (poorly invasive phenotype) human gastric cancer cell lines (15). To identify invasion-achievable genes, SNU-638 cDNA was used as a tester. About 230 subtracted cDNA clones were obtained after subtraction, and then, differential screening revealed that 35 cDNA clones were overexpressed in SNU-638 as compared to SNU-484 cells. After sequencing and Northern blot analyses, eight different genes were finally identified as overexpressed in SNU-638 cells (Table I). Of these, the expression of met proto-oncogene (MET), calcium binding protein S100A6 (S100A6), translationally controlled tumor protein $1(T P T 1)$ and urokinase-type plasminogen activator $(P L A U)$ have already been known to be associated with enhanced malignancy of various types of human cancers including gastric cancer (16-21). To further confirm the expression of these candidate genes, we selected six genes and analyzed the expression by Northern blot analysis in several human gastric cancer cell lines (Figs. 1 and 2A), which had been established from primary tumors (SNU-1 and SNU-484) or secondary tumor sites (SNU-5, -16, -216, -620 and -638). Notably, we identified the AAH transcript variant 3 (humbug) as an overexpressed gene in the cell lines 
Table I. Summary of overexpressed genes in SNU-638 cells.

\begin{tabular}{lcccc}
\hline Clone & Sequence identity & Accession number & Redundancy & Expression $^{\mathrm{a}}$ \\
\hline G1 & Met & NM_000245 & 5 & $>10$ \\
G2 & S100A6 & NM_014624 & 14 & $>10$ \\
G3 & FTH1 & NM_002032 & 4 & ND $^{\mathrm{b}}$ \\
G4 & TPT1 & NM_003295 & 4 & 5.6 \\
G5 & AKAP12 & NM_005100 & 3 & $>10$ \\
G6 & PLAU & NM_002658 & 3 & 8.5 \\
G7 & UBE2E1 & NM_182666 & 1 & 7.8 \\
G8 & Humbug & NM_032466 & 1 & $>10$ \\
\hline
\end{tabular}

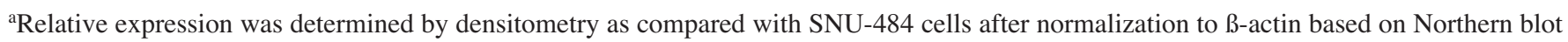
analysis. The values represent fold expression compared to SNU-484 cells. ${ }^{b} \mathrm{ND}$, Not determined.

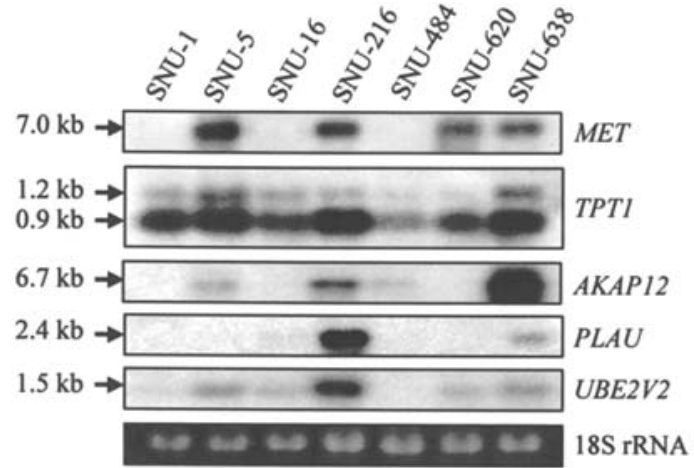

Figure 1. Expression of the selected genes in various human gastric cancer cell lines. Northern blot was performed to determine the mRNA expression level of MET, TPT1, AKAP12, PLAU and UBE2V2 from the indicated human gastric cancer cell lines. To represent an equal loading of nondegraded RNA, 18S rRNA stained with ethidium bromide is shown at the bottom of the panel.

established from secondary tumor sites such as SNU-5, -16, -216 and -638 cells (Table I and Fig. 2). Therefore, we further investigated a possible role of humbug in metastatic progression of gastric cancer cells.

A homology search of clone G8 revealed the perfect match with AAH transcript variant 3 (accession no. NM_032466, corresponding position of clone 8: 1866 to $2284 \mathrm{bp}$ ), which encodes an isoform of AAH missing the catalytic domain. We compared the expression profiles between AAH and humbug by Northern blot analysis in various human gastric cancer cell lines (Fig. 2). When clone G8 was used as a probe (Fig. 2A), only a $2.9 \mathrm{~kb}$ transcript corresponding to humbug was detected (9). When a specific cDNA probe for recognizing both $A A H$ and humbug was used (Fig. 2B), two transcripts, which encode AAH (4.3 kb transcript) and humbug (2.9 kb transcript), respectively, were detected (9). These results suggest that $A A H$ and humbug were overexpressed in highly invasive gastric cancer cell lines.

Previous studies have shown that $A A H$ is overexpressed in hepatocellular carcinoma, cholangiocarcinoma and neuroblastoma and induces malignant transformation and cell motility (22-26). Therefore, we examined whether humbug,
A)

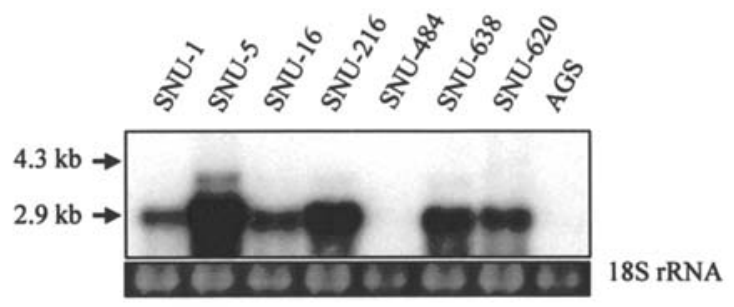

B)

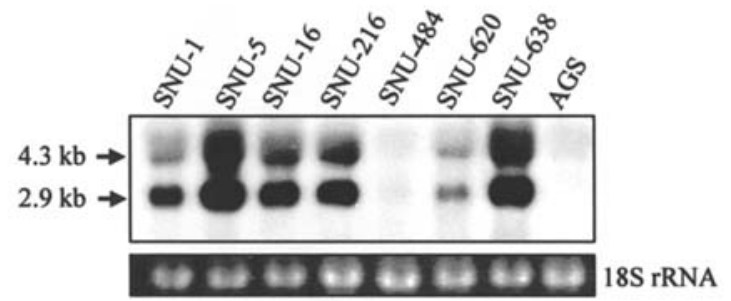

Figure 2. Expression of humbug and $A A H$ in various human gastric cancer cell lines. Northern blot was performed to determine the mRNA expression level of humbug (A) and $A A H(\mathrm{~B})$ from the indicated human gastric cancer cell lines. To represent an equal loading of non-degraded RNA, 18S rRNA stained with ethidium bromide is shown at the bottom of the panel.

which is a truncated form of aspartyl ß-hydroxylase missing the catalytic domain, modulates the malignant transformation of gastric cancer. To test this, AGS cells, which barely express humbug (Fig. 2A), were transfected with a FLAGtagged humbug expression vector or with the vector alone. After selection in G418, the pooled population of G418resistant humbug-transfected and empty vector-transfected AGS cells were obtained and designated AGS/hum and AGS/neo, respectively. To rule out the clonal variation of AGS cells, we used AGS/hum and AGS/neo without clonal selection for further experiments. The protein expression of exogenous humbug in AGS/hum cells was confirmed by Western blot analysis using an anti-FLAG monoclonal antibody (Fig. 3A). The exogenous humbug was detected as a 
A)

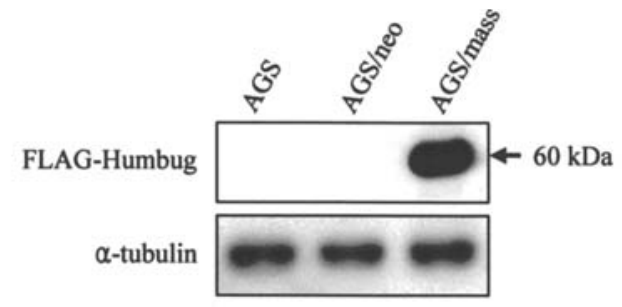

B)

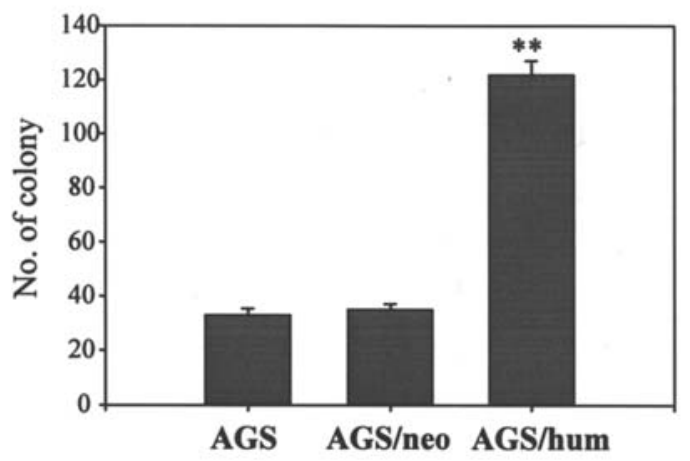

C)

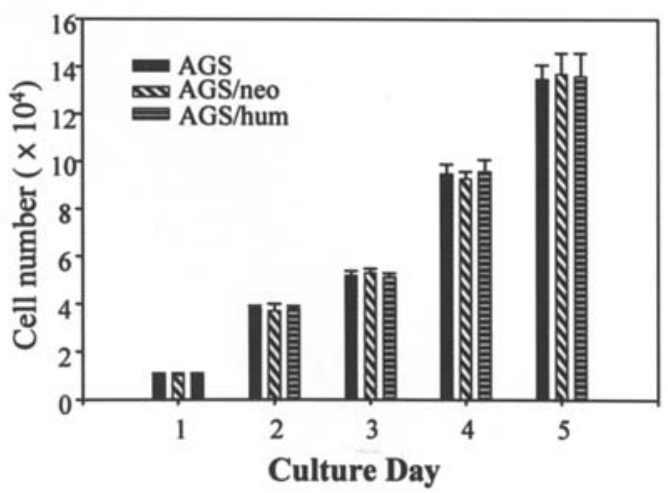

Figure 3. Humbug stimulates anchorage-independent growth of AGS cells (A) Expression of the humbug protein by stably transfected AGS cells as shown by Western blotting. AGS cells were stably transfected with either the empty pCMV-Tag $2 \mathrm{~A}$ vector (AGS/neo) or the humbug expression vector (AGS/mass), respectively. Cell lysates $(50 \mu \mathrm{g})$ were immunoblotted with an anti-FLAG M2 monoclonal antibody. The bottom represents $\alpha$-tubulin to show the equal loading of cell lysates. (B) Effect of humbug overexpression on colony formation of AGS cells in $0.3 \%$ agar. (C) Effect of humbug overexpression on the proliferation of AGS cells. Data represent (average \pm S.E) of three independent experiments performed in triplicate; ${ }^{* *} \mathrm{p}<0.01$ vs. vector-transfectants (one-way ANOVA).

single band at $60 \mathrm{kDa}$ in AGS/mass, though not in AGS/neo and the parental. The size of humbug observed in Western blot is consistent with the previous report (9). We examined whether humbug affected the ability of anchorage-independent growth of AGS cells. The ability of humbug-transfectants to exhibit anchorage-independent cell growth was examined using a colony formation assay in $0.3 \%$ agar. AGS/hum cells showed increased anchorage-independent growth as compared to parental AGS and AGS/neo cells (Fig. 3B). The extent of colony formation in $0.3 \%$ agar was 3.5 -fold higher for AGS/hum as compared with the AGS/neo ( $p<0.01$, one-way ANOVA). The mean \pm S.E. of colony formed per well for
A)

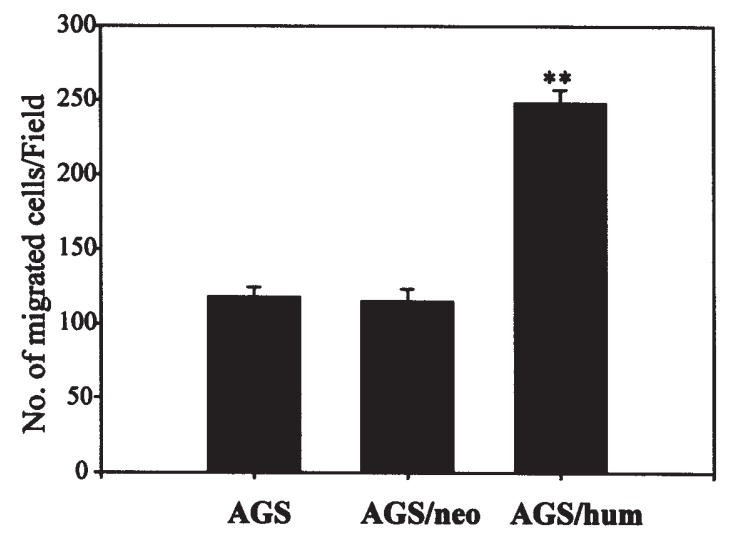

B)

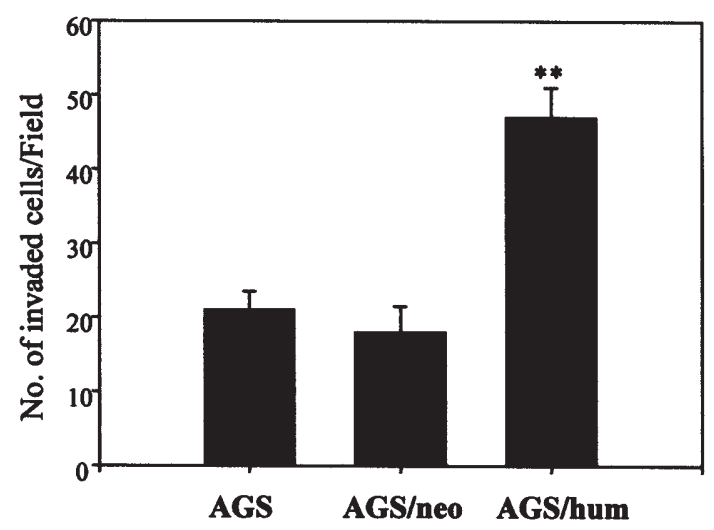

Figure 4. Humbug stimulates cell migration and invasion in AGS cells. Cells that migrated (A) or invaded (B) through the pores in the filter were fixed, stained and counted in five random fields visualized by microscopy (x100). Data represent (average \pm S.E) three independent experiments performed in triplicate; ${ }^{* *}$ p $<0.01$ vs. vector-transfectants (one-way ANOVA).

AGS, AGS/neo, and AGS/mass was $33 \pm 2.4,35 \pm 2.1$ and $122 \pm 5.1$, respectively. However, the proliferation of AGS/mass cells was similar to that of parental AGS and AGS/neo (Fig. 3C). Then, we examined whether overexpression of humbug could affect migration and invasion of AGS cells using a Transwell migration assay. AGS/mass cells exhibited increased cell migration through filters as compared to parental AGS and AGS/neo cells (Fig. 4A). The extent of migrated cells was 2.1-fold higher for AGS/mass as compared with the AGS/neo ( $\mathrm{p}<0.01$, one-way ANOVA). The mean \pm S.E. of migrated cells per field (x100) for AGS, AGS/neo and AGS/mass was $118 \pm 6.4,115 \pm 8.1$ and 248.4 \pm 9.1 , respectively. Similar results were obtained from an invasion assay using Matrigel-coated filters (Fig. 4B). AGS/hum cells showed significantly increased invasiveness over that of the vector-transfected control ( $\mathrm{p}<0.01$, one-way ANOVA).

\section{Discussion}

In the present study, we found that humbug is overexpressed in human gastric cancer cell lines and the level of its expression is correlated with the invasive potential of various gastric cancer cell lines. Furthermore, we provided evidence 
for the direct role of humbug in gastric cancer progression by promoting cell invasion and anchorage-independent growth. Previous studies demonstrated that $A A H$ is abundantly expressed in a broad range of malignant neoplasms and transformed cell lines, including those of hepatic, biliary, breast, colon, pulmonary, pancreatic and neural origin (22-26). Overexpression of $A A H$ is associated with malignant transformation and increased cell motility in several types of cancer cell lines (22-26). In contrast, the expression level and role of the humbug gene in human cancer has not been clarified. A recent report revealed that humbug is overexpressed and may be a useful prognostic marker for colon cancer (27). This report showed that expression levels of humbug correlate with histological grade and tumor behavior. However, expression of AAH was not correlated with tumor grade or survival. Herein, we demonstrated that humbug, a truncated form of AAH missing the catalytic domain, is overexpressed and may induce the malignant transformation of human gastric cancer cells.

How might humbug increase anchorage-independent cell growth and cell motility? The molecular mechanisms by which AAH regulates cell motility are uncertain; however, evidence suggests that AAH may mediate its effects on cell migration by activating notch signaling pathways. In this regard, functional studies have demonstrated that AAH catalyzes post-translational hydroxylation of $B$ carbons of aspartyl and asparaginyl residues present in EGFlike domains of certain proteins $(8,28,29)$. The consensus sequence for $\mathrm{AAH}$ hydroxylation is present in the EGF-like domains of notch, notch homologs and the ligand jagged (8). Humbug is a truncated form of AAH missing catalytic domain of the B-hydroxylase, though in spite of the absence of enzymatic activity, it can increase anchorage-independent growth, invasion and motility of human gastric cancer cells. Humbug is derived from the first 14 exons of the AAH gene and can bind calcium $(8-10,23)$. Overexpression of humbug increases intracellular calcium levels by promoting its release from intracellular stores $(10,11)$. Since calcium levels have a critical role in regulating various signaling pathways, increased humbug expression may be important for modulating changes in cell shape, cellular adhesion and migration that mediate tumor progression.

Collectively, our results indicate that overexpression of humbug can/may promote cell migration and anchorageindependent growth in human gastric cancer cell lines and suggests a potential role for humbug in the processes of tumor cell migration, invasion and possibly metastasis. Further study to evaluate the functions and regulation mechanisms of humbug will expand our understanding of the role played by humbug in tumor progression and may provide a useful prognostic marker for gastric cancer.

\section{Acknowledgements}

This study was supported by a 2007 Research Grant from Kangwon National University.

\section{References}

1. Parkin DM, Bray F, Ferlay J and Pisani P: Global cancer statistics. CA Cancer J Clin 5: 74-108, 2002.
2. Roukos DH: Current status and future perspectives in gastric cancer management. Cancer Treat Rev 26: 243-255, 2000.

3. Yoo CH, Noh SH, Shin DW, Choi SH and Min JS: Recurrence following curative resection for gastric carcinoma. Br J Surg 87: 236-242, 2000.

4. Fidler IJ: The pathogenesis of cancer metastasis: the 'seed and soil' hypothesis revisited. Nat Rev Cancer 3: 453-458, 2003.

5. Oue N, Aung PP, Mitani Y, Kuniyasu H, Nakayama H and Yasui W: Genes involved in invasion and metastasis of gastric cancer identified by array-based hybridization and serial analysis of gene expression. Oncology 69: 17-22, 2005.

6. Oue N, Hamai Y, Mitani Y, Matsumura S, Oshimo Y, Aung PP, Kuraoka K, Nakayama H and Yasui W: Gene expression profile of gastric carcinoma: identification of genes and tags potentially involved in invasion, metastasis, and carcinogenesis by serial analysis of gene expression. Cancer Res 64: 2397-2405, 2004.

7. Aung PP, Oue N, Mitani Y, Nakayama H, Yoshida K, Noguchi T, Bosserhoff AK and Yasui W: Systematic search for gastric cancerspecific genes based on SAGE data: melanoma inhibitory activity and matrix metalloproteinase-10 are novel prognostic factors in patients with gastric cancer. Oncogene 25: 2546-2557, 2006.

8. Dinchuk JE, Focht RJ, Kelley JA, Henderson NL, Zolotarjova NI, Wynn R, Neff NT, Link J, Huber RM, Burn TC, Rupar MJ, Cunningham MR, Selling BH, Ma J, Stern AA, Hollis GF, Stein RB and Friedman PA: Absence of post-translational aspartyl beta-hydroxylation of epidermal growth factor domains in mice leads to developmental defects and an increased incidence of intestinal neoplasia. J Biol Chem 277: 12970-12977, 2002.

9. Dinchuk JE, Henderson NL, Burn TC, Huber R, Ho SP, Link J, O'Neil KT, Focht RJ, Scully MS, Hollis JM, Hollis GF and Friedman PA: Aspartyl beta-hydroxylase (Asph) and an evolutionarily conserved isoform of Asph missing the catalytic domain share exons with junctin. J Biol Chem 275: 39543-39554, 2000 .

10. Ho SP, Scully MS, Krauthauser CM, Wexler EJ, Stow MD, Dinchuk JE, Kerr JS and Friedman PA: Antisense oligonucleotides selectively regulate aspartyl beta-hydroxylase and its truncated protein isoform in vitro but distribute poorly into A549 tumors in vivo. J Pharmacol Exp Ther 302: 795-803, 2002.

11. Treves S, Feriotto G, Moccagatta L, Gambari R and Zorzato F: Molecular cloning, expression, functional characterization, chromosomal localization, and gene structure of junctate, a novel integral calcium binding protein of sarco(endo)plasmic reticulum membrane. J Biol Chem 275: 39555-39568, 2000.

12. Park JG, Frucht H, LaRocca RV, Bliss DP, Kurita Y, Chen TR, Henslee JG, Trepel JB, Jensen RT, Johnson BE, Bang YJ, Kim JP and Gazdar AF: Characteristics of cell lines established from human gastric carcinoma. Cancer Res 50: 2773-2780, 1990.

13. Park JG, Yang HK, Kim WH, Chung JK, Kang MS, Lee JH, Oh JH, Park HS, Yeo KS, Kang SH, Song SY, Kang YK, Bang YJ, Kim YI and Kim JP: Establishment and characterization of human gastric carcinoma cell lines. Int J Cancer 70: 443-449, 1997.

14. Koo TH, Lee JJ, Kim EM, Kim KW, Kim HD and Lee JH: Syntenin is overexpressed and promotes cell migration in metastatic human breast and gastric cancer cell lines. Oncogene 21: 4080-4088, 2002

15. Lee DH, Yang Y, Lee SJ, Kim KY, Koo TH, Shin SM, Song KS, Lee YH, Kim YJ, Lee JJ, Choi I and Lee JH: Macrophage inhibitory cytokine-1 induces the invasiveness of gastric cancer cells by up-regulating the urokinase-type plasminogen activator system. Cancer Res 63: 4648-4655, 2003.

16. Houldsworth J, Cordon-Cardo C, Ladanyi M, Kelsen DP and Chaganti RS: Gene amplification in gastric and esophageal adenocarcinomas. Cancer Res 50: 6417-6422, 1990.

17. Komatsu K, Kobune-Fujiwara Y, Andoh A, Ishiguro S, Hunai H, Suzuki N, Kameyama M. Murata K, Miyoshi J, Akedo H, Tatsuta M and Nakamura H: Increased expression of S100A6 at the invading fronts of the primary lesion and liver metastasis in patients with colorectal adenocarcinoma. Br J Cancer 83: 769-774, 2000.

18. Vimalachandran D, Greenhalf W, Thompson C, Luttges J, Prime W, Campbell F, Dodson A, Watson R, Crnogorac-Jurcevic T, Lemoine N, Neoptolemos J and Costello E: High nuclear S100A6 (Calcyclin) is significantly associated with poor survival in pancreatic cancer patients. Cancer Res 65: 3218-3225, 2005.

19. Allgayer H, Heiss MM, Riesenberg R, Grutzner KU, Tarabichi A, Babic R and Schildberg FW: Urokinase plasminogen activator receptor (uPA-R): one potential characteristic of metastatic phenotypes in minimal residual tumor disease. Cancer Res 57: 1394-1399, 1997. 
20. Chung S, Kim M, Choi W, Chung J and Lee K: Expression of translationally controlled tumor protein mRNA in human colon cancer. Cancer Lett 156: 185-190, 2000.

21. Tuynder M, Susini L, Prieur S, Besse S, Fiucci G, Amson R and Telerman A: Biological models and genes of tumor reversion: cellular reprogramming through tpt1/TCTP and SIAH-1. Proc Natl Acad Sci USA 99: 14976-14981, 2002.

22. Lavaissiere L, Jia S, Nishiyama M, de la Monte S, Stern AM, Wands JR and Friedman PA: Overexpression of human aspartyl (asparaginyl) B-hydroxylase in hepatocellular carcinoma and cholangiocarcinoma. J Clin Invest 98: 1313-1323, 1996.

23. Ince N, de la Monte S and Wands JR: Overexpression of human aspartyl (asparaginyl) B-hydroxylase is associated with malignant transformation. Cancer Res 60: 1261-1266, 2000.

24. de la Monte SM, Tamaki S, Cantarini MC, Ince N, Wiedmann M, Carter JJ, Lahousse SA, Califano S, Maeda T, Ueno T, D'Errico A, Trevisani F and Wands JR: Aspartyl-(asparaginyl)beta-hydroxylase regulates hepatocellular carcinoma invasiveness. J Hepatol 44: 971-983, 2006.

25. Maeda T, Sepe P, Lahousse S, Tamaki S, Enjoji M, Wands JR and de la Monte SM: Antisense oligodeoxynucleotides directed against aspartyl (asparaginyl) B-hydroxylase suppress migration of cholangiocarcinoma cells. J Hepatol 38: 615-622, 2003.
26. Sepe PS, Lahousse SA, Gemelli B, Chang H, Maeda T, Wands JR and de la Monte SM: Role of the aspartyl-asparaginyl-betahydroxylase gene in neuroblastoma cell motility. Lab Invest 82: 881-891, 2002.

27. Wang J, de la Monte SM, Sabo E, Kethu S, Tavares R, Branda M, Simao L, Wands JR and Resnick MB: Prognostic value of humbug gene overexpression in stage II colon cancer. Hum Pathol 38: 17-25, 2007.

28. Gronke RS, Welsch DJ, VanDusen WJ, Garsky VM, Sardana MK, Stern AM and Friedman PA: Partial purification and characterization of bovine liver aspartyl beta-hydroxylase. J Biol Chem 265: 8558-8565, 1990

29. Jia S, McGinnis K, VanDusen WJ, Burke CJ, Kuo A, Griffin PR, Sardana MK, Elliston KO, Stern AM and Friedman PA: A fully active catalytic domain of bovine aspartyl (asparaginyl) Bhydroxylase expressed in Escherichia coli: characterization and evidence for the identification of an active-site region in vertebrate alpha-ketoglutarate-dependent dioxygenases. Proc Natl Acad Sci USA 91: 7227-7231, 1994. 